\title{
Efeito do maturador e manejo de secagem na qualidade do café cereja descascado ${ }^{1}$
}

\author{
Paulo Cesar Bacolli Moreira ${ }^{2}$, Kleso Silva Franco Júnior ${ }^{2}$, Giselle Prado Brigante ${ }^{2}$, Marcio de Souza \\ Dias $^{3}$
}

Resumo: A colheita do café é uma das atividades mais onerosas e impacta diretamente no custo de produção e qualidade, portanto é uma etapa que merece muita ateção. Porém, uma das limitações da colheita, seja no sistema manual ou mecanizado, é a desuniformidade de maturação, que prejudica o desempenho operacional e a qualidade do produto final, gerando perdas econômicas aos produtores. A presente pesquisa foi desenvolvida na Fazenda Santa Rita, município de Machado - MG, e objetivou avaliar o tempo de secagem, a qualidade física e sensorial do café cereja descascado com e sem aplicação de etileno, submetidos a três manejos de secagem. O experimento instalado em esquema fatorial 3 x 2 ( 3 metodologias de secagem associado a sem e com uso de etileno) em blocos casualizados com 4 repetições para cada tratamento, totalizando 24 unidades experimentais, com 30 litros de café cada. Foram colhidos 5500 litros de café da gleba que foi submetida à aplicação de etileno, e da gleba que não foi submetida, processados até obter a porção cereja descascado dos lotes. Após a secagem, as amostras foram submetidas a um período de descanso de 30 dias, beneficiadas e enviadas para análises de qualidade. Foi analisado o tempo de secagem a qualidade através da prova de xícara pela metodologia SCAA por 3 classificadores de instituições credenciadas. Entre os métodos de secagem orientado terreiro concreto, normal terreio concreto e suspendo orientado recomenda-se o primeiro por proporcionar menor tempo de secagem e não haver diferenças na qualidade do café. A aplicação do etileno não interferiu nas características avaliadas.

Palavras-chave: Coffea arabica L; Processamento; Prova de xícara SCAA.

\section{Effect of ripening and drying management on the quality of peeled cherry coffee}

\begin{abstract}
Coffee harvesting is one of the most costly activities and directly impacts production costs and quality, so it is a step that deserves a lot of attention. However, one of the limitations of the harvest, whether in the manual or mechanized system, is the unevenness of maturation, which affects the operational performance and the quality of the final product, generating economic losses for producers. This research was carried out at Fazenda Santa Rita, in the city of Machado - MG, and aimed to evaluate the drying time, the physical and sensory quality of the peeled cherry coffee with and without ethylene application, submitted to three drying procedures. The experiment installed in a $3 \times 2$ factorial scheme ( 3 drying methodologies associated with and without the use of ethylene) in randomized blocks with 4 repetitions for each treatment, totaling 24 experimental units, with 30 liters of coffee each. 5500 liters of coffee were harvested from the plot that was submitted to the application of ethylene, and from the plot that was not submitted, processed until obtaining the peeled cherry portion of the lots. After drying, the samples were subjected to a rest period of 30 days, processed and sent for quality analysis. The quality drying time was analyzed through the cup test using the SCAA methodology by 3 classifiers from accredited institutions. Among the drying methods oriented concrete terrace, normal concrete terrace and guided suspension, the first is recommended because it provides less drying time and there are no differences in the quality of the coffee. The application of ethylene did not interfere with the evaluated characteristics.
\end{abstract}

Keywords: Coffea arabica L; Processing; Cup-proof SCAA.

${ }^{1}$ Submetido em 30/04/2019 e aprovado em 16/12/2020;

${ }^{2}$ Centro Superior de Ensino e Pesquisa de Machado, Faculdade de Agronomia, Machado, Minas Gerais, Brasil E-mail: paulobaccoli7@hotmail.com - ORICD: https://orcid.org/0000-0002-0827-4001; klesojr@gmail.com (Autor correspondente) - ORICD: https://orcid.org/0000-0002-6807-8889; giselle.brigante@gmail.com - ORICD: https://orcid.org/0000-0002-0952-0075;

${ }^{3}$ Secretária de Educação de Minas Gerais, Departamento de Biologia, Serrania, MG, Brasil; E-mail: marciodesouzadias2013@gmail.com ORICD: https://orcid.org/0000-0001-8367-1341

Agropecuária Técnica, Areia-PB, v. 41, n. 3-4, p. 78-82, 2020

https://doi.org/10.25066/agrotec.v41i3-4.45645 


\section{Introdução}

O Brasil é líder mundial na produção de café, representando $36 \%$ da produção mundial cuja a produção mundial (2019-2020) foi estimada em torno de 169,34 milhões de saca de $60 \mathrm{~kg}$ pela Organização Internancional do Café (OIC, 2020). No entanto, as exigências do mercado internacional por cafés de melhor qualidade estão sendo responsáveis pela difusão e adoção de novas tecnologias de produção e preparo, pois um dos fatores que o mercado internacional tem dado muita atenção é em relação ao padrão de qualidade do produto nacional (Martins et al., 2005).

Em toda a cadeia produtiva do café, são vários os fatores que, se mal conduzidos, proporcionam a perda de qualidade do café, aumentam o risco sanitário e consequentemente reduzem sua remuneração (Reinato, 2006).

O café pode ser preparado de diferentes formas: natural, cereja descascado, despolpado e desmucilado. Na forma de preparo natural, o fruto é secado na sua forma integral (com casca e mucilagem). Desse modo o café poderá ir diretamente da lavoura para o terreiro, sendo secado com casca e mucilagem. No entanto tratase de uma forma de preparo com grandes riscos à qualidade do café, pois são secados cafés com diferentes estágios de maturação, diferentes teores de água, podendo ocorrer frutos com diversas anormalidades como brocados e mal granados. A passagem desse café pelo lavador apresenta inúmeras vantagens. A separação hidráulica dos frutos por diferença de densidade, permite a obtenção de três parcelas de café: a cereja, a verde e a porção bóia. A parcela de frutos cereja e verde constitui um material com potencial para a produção de café de melhor qualidade, devendo ser conduzida separadamente até o beneficiamento e comercialização (Souza, 2000).

O café cereja descascado pode ser considerado como um método intermediário entre o preparo natural e despolpado, pois mantém as características típicas do corpo, aroma e doçura dos cafés brasileiros. As principais vantagens do descascamento são a eliminação dos frutos verdes, a diminuição dos custos de beneficiamento e diminuição da porcentagem de bebidas de má qualidade. No entanto, muitos produtores que têm feito uso dessa tecnologia, não têm conseguido atingir a qualidade almejada, isso tem ocorrido devido à falta de cuidados nas etapas de pós-colheita principalmente durante a secagem.

$\mathrm{Na}$ tentativa de melhorar os aspectos na colheita, o uso de etileno objetiva converter frutos verdes em cereja, promovendo uma maior uniformidade de maturação, obtendo efeitos diretos na secagem e qualidade de bebida (Dias et al., 2014)

A maioria dos produtos agrícolas são colhidos ao ponto de maturidade fisiológica, quando apresentam teores máximos de proteínas e óleo, e teor de água elevado. Essa última condição é propícia ao desenvolvimento de fungos e insetos conduzindo à deterioração rápida, sendo necessária a remoção da água, que pode ser realizada pela secagem natural ou artificial.

Uma secagem de forma rápida minimiza o risco de fermentação indesejável. Isso evita a deterioração causada por micro-organismos, sendo a presença destes influenciada pelo tipo de pré-processamento. Um processo de secagem eficiente é aquele que, além de reduzir o teor de água do produto, aumenta seu potencial de conservação pós-colheita e preserva suas características físicas e propriedades tecnológicas, atribuindo-lhe alto valor comercial (Reinato, 2006).

Fazendo uma secagem completa em terreiros, podemos observar que a produção de café cereja descascado é o procedimento mais econômico, dentro das técnicas de pré-processamento estudadas, em todos os níveis de produção, para a secagem de café em terreiros de concreto.

Desse modo, a presente pesquisa foi desenvolvida como objetivo de avaliar o tempo da secagem e a qualidade física e sensorial do café cereja descascado com e sem aplicação de etileno, submetidos a diferentes metodologias de secagem.

\section{Material e Métodos}

A pesquisa foi realizada na Fazenda Santa Rita, município de Machado, MG, no período de Julho a Setembro de 2018. Segundo Köppen (1928), o clima é classificado como Cwa, com temperatura média anual de $20,3{ }^{\circ} \mathrm{C}$ e índice pluviométrico de $1.526 \mathrm{~mm}$. O solo é caracterizado como Latossolo Vermelho Amarelo 
e, de acordo com os resultados das análises granulométricas, apresenta textura média com $28 \%$ de argila, $43 \%$ de areia e $29 \%$ de silte, ou seja, tipo 2, segundo Santos et al. (2018).

$\mathrm{O}$ delineamento utilizado foi em blocos casualizados (DBC) em esquema fatorial $3 \times 2$, sendo o primeiro fator relativo aos três manejos de terreiro (manejo normal em terreiro de concreto, manejo orientado em terreiro de concreto e manejo orientado em terreiro suspenso) e o segundo fator relativo ao café cereja descascado (submetidos ou não à aplicação de etileno), ETEFOM $720 \mathrm{~g} / \mathrm{l}$, dosagem de 130 $\mathrm{ml} / 1001$ calda, 500 litros calda/ha de acordo com as especificações tecnicas da bula do produto comercial Etrhel ${ }^{\circledR} 720$, com quatro repetições, totalizando 24 parcelas experimentais.

O café utilizado foi um Catuaí Amarelo IAC 62, cultivado na Fazenda Santa Rita foi colhido de forma manual. Foram colhidos 5500 litros de café, equivalendo ao volume final de aproximadamente $660 \mathrm{~kg}$ de café beneficiado, levados para a Unidade de Pós-Colheita e lavados por diferença de densidade originando as porções bóia e cereja-verde. Posteriormente o café foi processado no descascador e o cereja foi descascado, dando origem ao cereja descascado. $\mathrm{O}$ mesmo procedimento aconteceu para a lote onde não recebeu a aplicação de etileno.

Cada parcela foi composta de 30 litros de café cereja descascado, os mesmos foram levados aos terreiros e dispostos em 6 tratamentos, ficando apresentados como: três tipos de manejo de terreiro (manejo normal no terreiro de concreto, manejo orientado no terreiro de concreto, manejo orientado no terreiro leito suspenso), dois tipos de café (com aplicação de etileno e sem a aplicação de etileno).

No manejo em terreiro de concreto (manejo tradicional da fazenda), com e sem etileno, o café foi esparramado em camada de $3 \mathrm{~cm}$ de espessura no primeiro e segundo dia, no terceiro dia a camada foi aumentada para $5 \mathrm{~cm}$ e no fim da tarde o café era coberto por um pano, o café foi rodado de 8 a 10 vezes por dia.

Em relação ao manejo orientado (manejo baseado em orientações técnicas), com e sem etileno, o café foi esparramado em camada de 1 grão de espessura nos dois primeiros dias, no terceiro dia a camada foi aumentada para $2 \mathrm{~cm}$, no fim da tarde o café foi coberto por um pano e foi rodado 16 vezes por dia.

Já o manejo em terreiro suspenso, com e sem etileno, o café foi esparramado em camada de 2 $\mathrm{cm}$ de espessura no primeiro e segundo dia, no terceiro dia a camada foi aumentada para $3 \mathrm{~cm}$, no fim da tarde o café era coberto por um pano e foi rodado 16 vezes por dia.

Os cafés que foram colhidos com aproximadamente $70 \%$ de umidade e durante a secagem foram realizadas amostragens para a determinação do teor de água, com intervalos regulares de um dia; até o café atingir $11 \%$ de umidade em base úmida, sendo contabilizado o número de dias gastos para que as amostras antigissem este teor de umidade.

Logo após a secagem as amostras passaram por um processo de descanso de 30 dias. Apos este periodo as mesmas foram beneficiadas e encaminhadas para análise de qualidade do café (prova de xícara, classificação por tipo /defeitos, cor e aspecto). Os dados foram submetidos à análise de variância e ao teste de comparação de médias, por meio do teste de Tukey a 5\% de significância por meio do software estatístico $\operatorname{SISVAR}^{\circledR}$ (Ferreira, 2014).

\section{Resultados e Discussão}

Após análise dos dados, verificou-se que houve diferença estatística em relação ao tempo de secagem (Tabela 1).

Tabela 1 Resumo das análises de variância para a médias dos dias para secagem (TS), nota da bebida (NB) e classificação quanto à defeitos (CD) de café em relação ao amanejo (M) e a aplicação de etileno (E)

\begin{tabular}{|c|c|c|c|c|}
\hline \multirow{2}{*}{ FV } & \multirow{2}{*}{ GL } & \multicolumn{3}{|c|}{ Quadrado Médio } \\
\hline & & TS & NB & $\mathrm{CD}$ \\
\hline Bloco & 3 & $2,44^{\mathrm{ns}}$ & $1,6653^{\text {ns }}$ & $11,12^{\text {ns }}$ \\
\hline Manejo (M) & 2 & $30,806^{*}$ & $0,681^{\text {ns }}$ & $6,1066^{\mathrm{ns}}$ \\
\hline Etileno $(\mathrm{E})$ & 1 & $1,5000^{\mathrm{ns}}$ & $1,2150^{\mathrm{ns}}$ & $29,13^{\text {ns }}$ \\
\hline $\mathrm{M} \times \mathrm{E}$ & 2 & $0,500^{\text {ns }}$ & $0,0650^{\mathrm{ns}}$ & $122,10^{\text {ns }}$ \\
\hline Resíduo & 15 & $64,1^{\mathrm{ns}}$ & $98,66^{\mathrm{ns}}$ & $547,65^{\text {ns }}$ \\
\hline $\mathrm{CV}(\%)$ & & 12,55 & 22,74 & 29,69 \\
\hline Média & & 9,63 & 81,23 & 26,74 \\
\hline
\end{tabular}

A Tabela 2 mostra que os diferentes manejos de secagem do café proporcionaram diferença no tempo de secagem onde o manejo orientado em terreiro de concreto foi o mais rápido; o manejo normal em terreiro de concreto intermediário e a secagem em terreiro suspenso sendo o mais lento. 
Em relação ao uso do etileno, observa-se que o mesmo não teve diferença estatistica entre os tratamentos.

Tabela 2 Média dos dias para secagem do café em cada manejo

\begin{tabular}{lccc}
\hline \multicolumn{1}{c}{ Manejo } & \multicolumn{3}{c}{ Etileno } \\
& Sem & Com & Média \\
\hline $\begin{array}{l}\text { Orientado terreiro } \\
\text { Concreto }\end{array}$ & 6,86 & 6,12 & $6,49 \mathrm{a}$ \\
Normal terreiro & & & $7,80 \mathrm{ab}$ \\
concreto & 8,10 & 7,50 & \\
$\begin{array}{l}\text { Suspenso orientado } \\
\text { Média }\end{array}$ & 14,12 & 13,8 & $13,96 \mathrm{~b}$ \\
*Médias seguidas pela mesma letra na coluna não diferem \\
entre si pelo teste de Tukey $(\mathrm{p} \leq 0,05)$.
\end{tabular}

Avaliando o tempo de secagem, foi constatado que os terreiros de leito suspenso demandam maior período de secagem, em torno de 14 dias, corroborando com o trabalho de Hardoim et al. (2001), que também encontraram resultados semelhantes, comparando com terreiro de lama asfáltica, qual demandou 8 dias para realizar a secagem.

Na pesquisa realizada por Reinato (2006), no processamento em terreiro de concreto, todos os tratamentos secaram antes do leito suspenso, de terra e terreiro de pano de polietileno, recomendando a secagem em terreiros concretados, pois favorecem a secagem mais rápida e a obtenção de cafés de melhor qualidade.

Os resultados referentes à bebida não tiveram diferenças significativas entre si, onde todos os manejos condicionaram bebida dura, o mesmo aconteceu para a uso ou não do etileno.

Os métodos de secagem adotados não influenciaram na classificação da bebida, independentemente do tratamento utilizado, todas as amostras de café resultaram em bebida dura. Estes resultados estão de acordo com os relatados por Felipe (2003), porém diferem de Reinato (2006), que constatou que a secagem em camadas grossas contribui negativamente para a qualidade de bebida do café.

Para os parâmetros defeitos dos grãos de café, não houve diferenças significativas entre os manejos.

Os cafés com etileno e sem etileno foram semelhantes entre si, quando os parâmetros analisados foram os defeitos.

Resultados parecidos foram encontrados por
Garcia et al. (2000), estudando o efeito de etileno na dosagem de $130 \mathrm{~mL}$ do produto comercial por 100 litros de água, verificando que houve um aumento significativo na porcentagem de frutos maduros, quando comparado com cafeeiros não tratados, porém, os resultados de classificação nas amostras revelaram uma grande semelhança no que diz respeito ao número de defeitos.

\section{Conclusão}

Entre os métodos de secagem orientado terreiro concreto, normal terreio concreto e suspendo orientado recomenda-se o primeiro por proporcionar menor tempo de secagem e não haver diferenças na qualidade do café. A aplicação do etileno não interferi nas características avaliadas.

\section{Referências}

Dias, R. E. B. A.; Silva, F. M.; Cunha, J. P. B; Avelar, R. C; Fernandes, F. C. Eficiência da colheita mecanizada do café com o uso do inibidor de biossíntese de etileno. Coffee Science, v. 9, n. 4, p. 516-526, 2014. http://www.sbicafe.ufv.br:80/handle/123456789/8078

Felipe, C. R. Crescimento, estado sanitário e produtividade de cafeeiros recepados (Coffea arabica L.) sob diferentes espaçamentos e influência do método de secagem na classificação e qualidade da bebida. 2003, 121 f. Dissertação (Mestrado em Ciências Agrárias). Faculdade de Agronomia e Medicina Veterinária, Universidade de Brasília, Brasília.

Ferreira, D. F. Sisvar: um guia dos seus procedimentos de comparações múltiplas Bootstrap. Ciência e Agrotecnologia, v. 38, n. 2. p. 109-112, 2014. https://doi.org/10.1590/S141370542014000200001

Garcia, A. W. R.; Teixeira, A. A.; Japiassú, L. B.; Frota, L. B.; Ferreira, R.A. In: Congresso Brasileiro de Pesquisas Cafeeiras, 26., 2000, Marília. Resumos... Rio de Janeiro: MAA/PROCAFE, 2000. p. 295-297.

Hardoim, P. C.; Borém, F. M.; Hardoim, P. R.; Abrahão, E. J. Secagem de café cereja, bóia e cereja desmucilado em terreiro de concreto, de lama asfáltica, de chão batido e de leito suspenso em Lavras. In: CONGRESSO BRASILEIRO DE PESQUISAS CAFEEIRAS, 2001, Uberaba, MG. Anais... Rio de Janeiro: PROCAFÉ, 2001. p. 126-128. 
KÖPPEN, W.; GEIGER, R. Klimate der Erde. Gotha: Verlag Justus Perthes. 1928. Wall-map $150 \mathrm{~cm} \times 200 \mathrm{~cm}$.

Martins, D. R.; Camargo, O. A.; Bataglia, O. C. Tecnologia pós-colheita - Qualidade do grão e da bebida em cafeeiros tratados com lodo de esgoto. Bragantia, Campinas, v. 64, n. 1, p. 115-126, 2005. Disponível em: < https://www.redalyc.org/pdf/908/90864113.pdf >. Acesso em: 29 agosto 2019.

\section{Reinato, C. H. R. Secagem e armazenamento do} café: aspectos qualitativos e sanitários. 2006. 11 p. Tese (Doutorado em Ciência dos Alimentos) - Universidade Federal de Lavras, Lavras, 2006.

Disponível

em http://repositorio.ufla.br/jspui/handle/1/2803 >. Acesso em: 12 julho 2019.

Santos, H. G.; Jacomine, P. K. T.; Anjos, L. H. C.; Oliveira, V. A.; Lumbreras, J. F.; Coelho, M. R.; Almeida, J. A.; Araujo Filho, J. C.; Oliveira, J. B.; Cunha, T. J. F. Sistema Brasileiro de Classificação de Solos. 5. ed. Brasília: Embrapa, 2018. 187p. Disponível em: < https://www.embrapa.br/solos/busca-de-publicacoes//publicacao/1094003/sistema-brasileiro-de-classificacaode-solos >. Acesso em: 12 dezembro 2020.

Souza, S. M. S. Produção de café de qualidade: II - Colheita, preparo e qualidade do café. Lavras: EPAMIG, 2000. 4p. (Circular Técnica $\left.\mathrm{n}^{\mathrm{o}} 118\right)$. 